\title{
Diagnostic Accuracy of FNAC in Relation to Histopathology in Bone Tumors
}

\author{
Authors \\ Dr Pooja Kanwat ${ }^{1}$, Dr Laxmi Narayan Meena ${ }^{2}$, Dr Kusum Mathur ${ }^{3}$ \\ Dr Abhilasha Garg ${ }^{4}$, Dr Mahak Sharma ${ }^{5}$ \\ ${ }^{1}$ Senior Resident, Department of Pathology, RNT Medical Collage, Udaipur, Rajasthan \\ ${ }^{2}$ Senior Resident, Department of Orthopaedics, RNT Medical College, Udaipur, Rajasthan \\ ${ }^{3}$ Professor, Department of Pathology, SMS Medical College, Jaipur, Rajasthan \\ ${ }^{4}$ Assistant Professor, Department of Pathology, RNT Medical College Udaipur Rajasthan \\ ${ }^{5}$ Senior Demonstrator, Department of Pathology, Assam Medical College and Hospital, Dibrugarh, Assam \\ Corresponding Author \\ Dr Pooja Kanwat
}

117, Vardhman Nagar - B , 200 Feet Bye Pass, Jaipur, Rajasthan, Pin - 302019

Email: drpoojakanwat830@ gmail.com contact number-7220952296

\begin{abstract}
Background: Bone tumors constitute approximately $1 \%$ of all tumors affecting the human body. The key to their accurate recognition is the utilization of an integrated approach that assesses and correlates the clinical, radiological, morphological and biological behaviour of these lesions.

Method: After complete clinical and plain radiographic examinations, FNAC was done. All eligible cases of bone tumors undergoing FNAC, slides were stained by $H \& E$ and $M G G$ and confirmed by histopathological diagnosis

Results: In our study out of 117 cases of bone tumors, satisfactory aspiration was obtained in 100 cases , 17 cases were unsatisfactory and 7 cases were misdiagnosed. 100 cases could be correlated and 93\% correlation was obtained. Whereas sensitivity, specificity, positive predictive value and negative predictive value were $93.4 \%, 92.5 \%, 91.4 \%$ and $94.3 \%$ respectively

Conclusion: Fine-needle aspiration of bone is a simple, reliable, and accurate diagnostic technique that can facilitate patient management and preoperative decision-making and/or avoid unnecessary invasive procedures.

Keywords - FNAC, bone tumors, cyto-histo correlation
\end{abstract}

\section{Introduction}

Fine Needle Aspiration cytology is a quick, safe, cheap and reliable diagnostic tool for the evaluation of masses from different sites in the body but it has not been widely applied in the diagnosis of bone tumours. This could be due to technical problems, the morphological heterogeneity of bone tumours and anticipated difficulty in obtaining adequate tissue material (Springfield DS et al 1996 and Kreicbergs A et al $1996)^{1,2}$. Martin and Ellis ${ }^{3}$ first applied this technique to the diagnosis of bone lesions in 1930 . Since then, several published series have yielded overall accuracy values ranging from $51 \%$ to 
$100 \%$ (Merce jorda M D et al 2000) ${ }^{4}$. It is important to realize that the final diagnosis of bone tumors should be made based on combined evaluation of clinical data, age of the patient, site of lesion, radiological findings and microscopic findings.

\section{Material and Methods}

Study is undertaken to evaluate diagnostic accuracy of FNAC in relation to histopathology in bone tumors and to find out sensitivity, specificity and diagnostic predictive value of FNAC in Bone tumours assuming histopathology as gold standard. It was carried out on 117 patients having bone lesions admitted in Orthopaedic ward or attending outdoor of Orthopaedic department, during period of 1 year. FNAC was performed as an outdoor procedure following which biopsy was sent to the department of pathology,. In fine needle aspiration cytology all cytosmears were stained with hematoxylin and eosin and May Grunwald Giemsa stains. The cytomorphological features were then recorded. Subsequently if the mass excised or an open biopsy is done, paraffin sections were prepared which stain with routine hematoxylin and eosin stains and special stain. Immunohistochemistry performed when required. The results of cytomorpholgy were then correlated with histopathology.

\section{Results}

Out of 117 cases, satisfactory aspiration was obtained in 100 cases and 17 cases were unsatisfactory. Out of these 100 cytosmears 7 cases were misdiagnosed on cytology. The diagnosis was consistent with histopathology in 93 cases . Benign tumors (59\%) occur more commonly than malignant tumors (41\%). Most common benign tumor was GCT (32.47\%).Among malignant bone tumors, Osteosarcoma was the most commonly occurring tumor (15\%). Most commonly occurring in $2^{\text {nd }}$ and $3^{\text {rd }}$ decade of life . 100 cases could be correlated and 93\% correlation was obtained. Whereas sensitivity, specificity, positive predictive value and negative predictive value were $93.4 \%, 92.5 \%, 91.4 \%$ and $94.3 \%$ respectively

TABLE - 1 Cyto-Histological Correlation In Bone Forming Tumors

\begin{tabular}{|c|c|c|c|c|c|c|}
\hline \multirow{2}{*}{$\begin{array}{l}\text { Name } \\
(n=19)\end{array} \quad$ tumor } & \multirow{2}{*}{$\begin{array}{l}\text { No. of } \\
\text { cases }\end{array}$} & \multicolumn{3}{|c|}{ Cytology } & \multirow{2}{*}{$\begin{array}{c}\text { Histo- } \\
\text { pathology }\end{array}$} & \multirow{2}{*}{$\begin{array}{l}\text { Number of } \\
\text { cases } \\
\text { Correlated }\end{array}$} \\
\hline & & Diagnostic & Mis- diagnosed & Unsatisfactory & & \\
\hline Osteoma & 3 & - & - & 3 & 3 & - \\
\hline Osteoblastoma & 4 & 2 & 1 & 1 & 4 & $2(67 \%)$ \\
\hline Osteosarcoma & 18 & 14 & 2 & 2 & 18 & $14(87 \%)$ \\
\hline Total & 25 & 16 & 3 & 6 & 25 & $16(84 \%)$ \\
\hline
\end{tabular}

Out of 25 cases of bone forming tumor, 3 cases of osteoma were unsatisfactory in cytology for evaluation, they were diagnosed on histopathology. 3 cases were misdiagnosed. A case of osteoblastoma was misdiagnosed as osteosarcoma on cytology. Out of 3 osteoblastoma, correlation were seen in two cases $(63.33 \%)$. Out of 18 cases of osteosarcoma, 2 cases were unsatisfactory and 2 cases were misdiagnosed as benign lesion. Out of 16 remaining cases, $87 \%$ cases show cyto-histological correlation. 
TABLE -2 Cyto-Histological Correlation In Cartilage Forming Bone Tumors

\begin{tabular}{|c|c|c|c|c|c|c|}
\hline \multirow{2}{*}{$\begin{array}{l}\text { Name } \\
\text { tumor }\end{array}$} & \multirow{2}{*}{$\begin{array}{l}\text { No. of } \\
\text { cases }\end{array}$} & \multicolumn{3}{|c|}{ Cytology } & \multirow{2}{*}{$\begin{array}{c}\text { Histo- } \\
\text { pathology }\end{array}$} & \multirow{2}{*}{$\begin{array}{c}\text { Number } \\
\text { of cases } \\
\text { correlated }\end{array}$} \\
\hline & & Diagnostic & $\begin{array}{c}\text { Mis- } \\
\text { diagnosed }\end{array}$ & Unsatisfactory & & \\
\hline Chondroma & 1 & 1 & - & - & 1 & $1(100 \%)$ \\
\hline Osteochondroma & 15 & 13 & - & 2 & 15 & $13(100 \%)$ \\
\hline Chondroblastoma & 1 & 1 & - & - & 1 & $1(100 \%)$ \\
\hline Chondromyxoid fibroma & 1 & 1 & - & - & 1 & $1(100 \%)$ \\
\hline Chondrosarcoma & 4 & 3 & 1 & - & 4 & $3(75 \%)$ \\
\hline Total & 22 & 19 & 1 & 2 & 22 & 19 (95\%) \\
\hline
\end{tabular}

In our study, out of 22 cases of cartilage forming bone tumors, 2 cases of osteochondroma were unsatisfactory on cytology, they were diagnosed by histopathology. One case of low grade chondrosarcoma was misdiagnosed as chondroma on cytology. Out of 20 cases, 19 cases could be correlated and $95 \%$ correlation was obtained.

TABLE - 3 Cyto-Histological Correlations In Other Bone Tumors

\begin{tabular}{|c|c|c|c|c|c|c|}
\hline \multirow{2}{*}{ Name of tumor } & \multirow{2}{*}{$\begin{array}{l}\text { No. of } \\
\text { cases }\end{array}$} & \multicolumn{3}{|c|}{ Cytology } & \multirow{2}{*}{$\begin{array}{l}\text { Histo- } \\
\text { Patholgy }\end{array}$} & \multirow{2}{*}{$\begin{array}{c}\text { Number } \\
\text { of cases } \\
\text { Correlated }\end{array}$} \\
\hline & & Diagnostic & $\begin{array}{c}\text { Mis- } \\
\text { Diagnosed }\end{array}$ & $\begin{array}{l}\text { Unsatis- } \\
\text { Factory }\end{array}$ & & \\
\hline Giant cell tumor & 38 & 32 & 3 & 3 & 38 & $32(91 \%)$ \\
\hline Ewing's sarcoma & 16 & 16 & - & - & 16 & $16(100 \%)$ \\
\hline Metastatic neoplasm & 9 & 9 & - & - & 9 & $9(100 \%)$ \\
\hline Aneurysmal bone cyst & 3 & - & - & 3 & 3 & - \\
\hline Non-ossifying fibroma & 2 & - & - & 2 & 2 & - \\
\hline Fibrous dysplasia & 1 & - & - & 1 & 1 & - \\
\hline Chordoma & 1 & 1 & - & - & 1 & $1(100 \%)$ \\
\hline Total & 70 & 58 & 3 & 9 & 70 & $58(95 \%)$ \\
\hline
\end{tabular}

Out of 70 cases of other bone tumors, 3 cases of GCT, 3 cases of aneurysmal bone cyst, 2 cases of ossifying fibroma and 1 case of fibrous dysplasia were unsatisfactory. 3 cases of GCT were misdiagnosed as spindle cell sarcoma. Out of 61 cases, 58 cases could be correlated and 95\% correlation was obtained. 


\section{JMSCR Vol||3||Issue ||10||Page 7904-7911||October}

TABLE - 4 Accuracy Of Cytological Diagnosis In Comparison With Histopathological Diagnosis

\begin{tabular}{|c|c|c|c|c|}
\hline $\begin{array}{l}\text { S. } \\
\text { No. }\end{array}$ & $\begin{array}{l}\text { Name of tumor } \\
\qquad(\mathbf{N}=100)\end{array}$ & Histopathological diagnosis & $\begin{array}{c}\text { Cytological } \\
\text { diagnosis }\end{array}$ & $\begin{array}{c}\% \text { accuracy of } \\
\text { cytological } \\
\text { diagnosis }\end{array}$ \\
\hline 1 & Osteoblastoma & 3 & 2 & $63 \%$ \\
\hline 2 & Osteosarcoma & 16 & 14 & $87 \%$ \\
\hline 3 & Chondroma & 1 & 1 & $100 \%$ \\
\hline 4 & Osteochondroma & 13 & 13 & $100 \%$ \\
\hline 5 & Chondroblastoma & 1 & 1 & $100 \%$ \\
\hline 6 & Chondromyxoid fibroma & 1 & 1 & $100 \%$ \\
\hline 7 & Chondrosarcoma & 4 & 3 & $75 \%$ \\
\hline 8 & Giant cell lesion & 35 & 32 & $91 \%$ \\
\hline 9 & Ewing's sarcoma & 16 & 16 & $100 \%$ \\
\hline 10 & Metastatic neoplasm & 9 & 9 & $100 \%$ \\
\hline \multirow[t]{2}{*}{11} & Chordoma & 1 & 1 & $100 \%$ \\
\hline & TOTAL & 100 & 93 & $93 \%$ \\
\hline
\end{tabular}

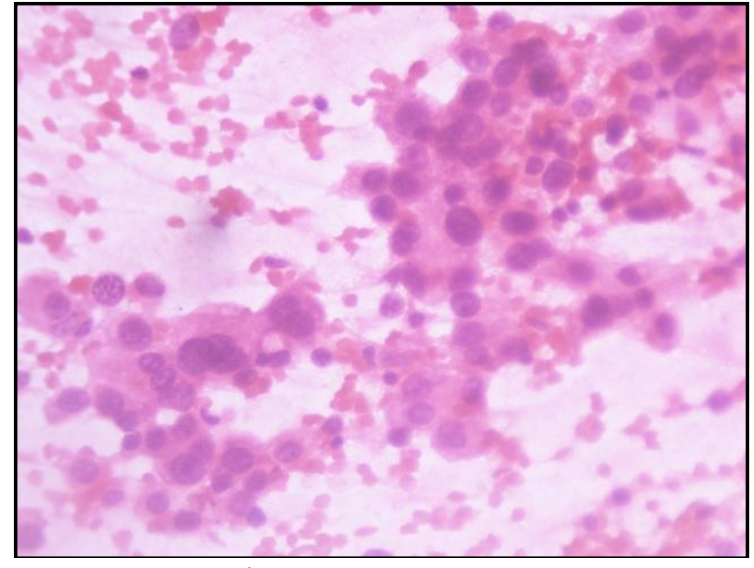

Figure : 1 (A)

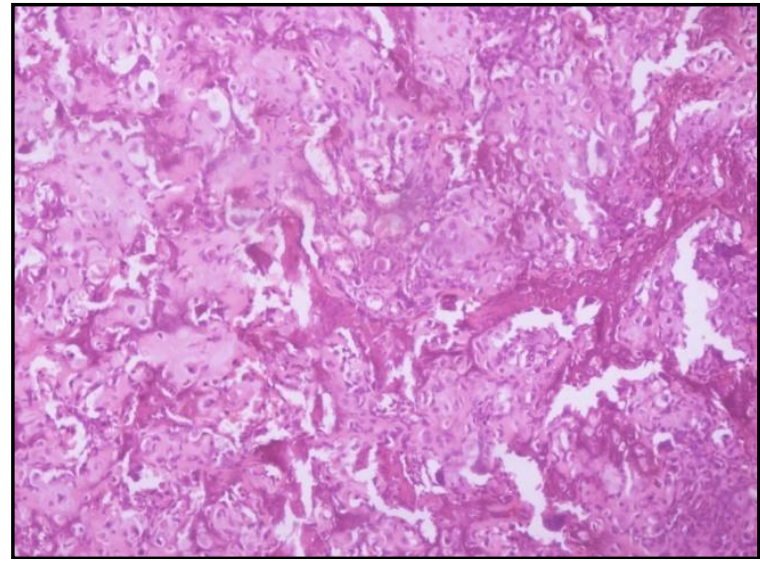

Figure :1 (B)

Figure 1 (A) FNA smear : Loose clusters of pleomorphic cells and multinucleated cells (H\&E, 400X) (B) Photomicrograph shows malignant osteoid formation by tumor cells (HP, H\&E, 100X) Osteosarcoma 


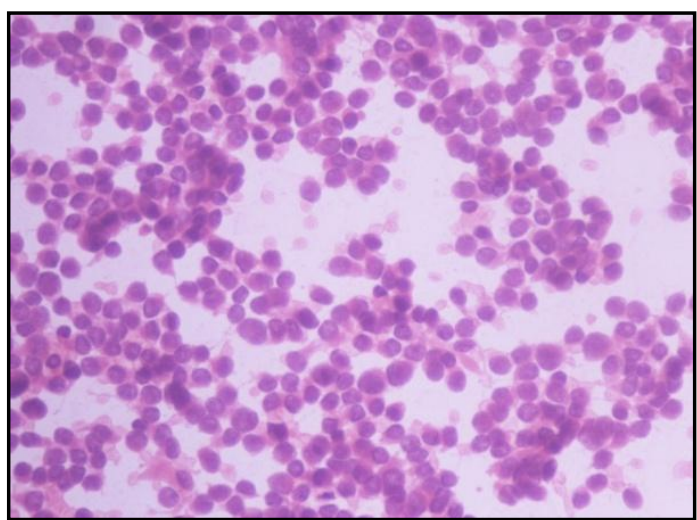

Figure : 2 (A)

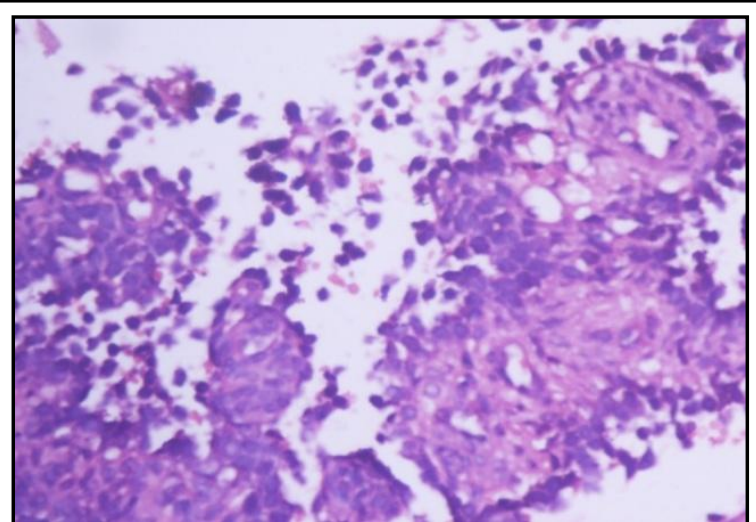

Figure : 2 (B)

Figure : 2 (A) FNA smear : Two cell type - Large cells with abundant cytoplasm and small dark cells with scant cytoplasm, Rosette like structure (H\&E, 400X). (B) Photomicrograph shows uniform cell with darkly stained nuclei and very scanty cytoplasm, some of the tumor cells arrange around the vessel in pseudorosette fashion (HP, H\&E, 400X) - Ewing's sarcoma

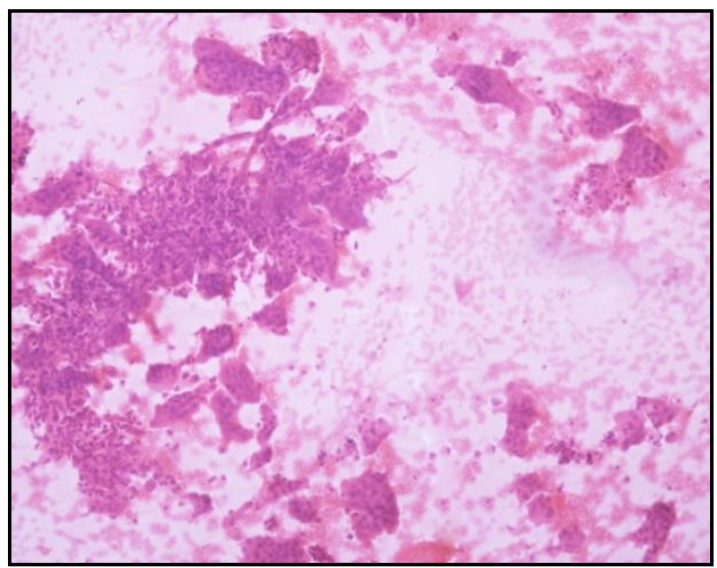

Figure : 3 (A)

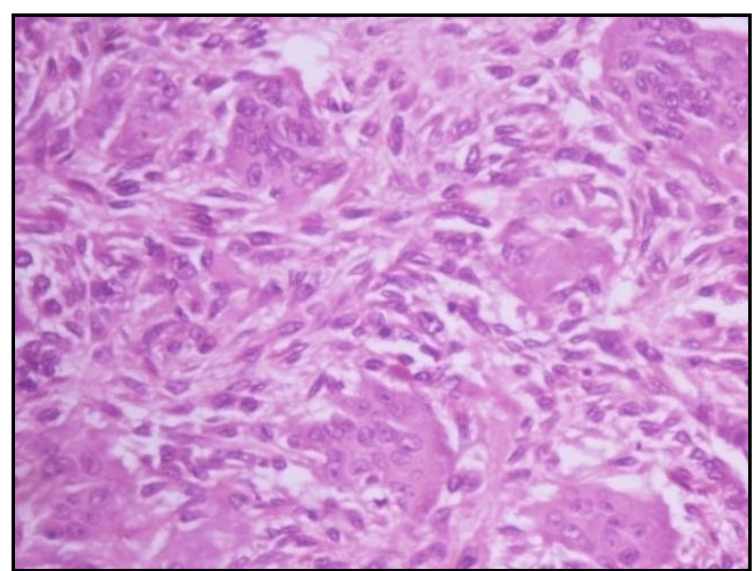

Figure : 3 (B)

Figure : 3 (A) FNA smear : Tissue fragment of cohesive plump spindle or ovoid cells ; multinucleated giant cells are located peripherally $(\mathrm{H} \& E$, 100X). (B) Photomicrograph show stromal cells and giant cells having 20-30 nuclei - (HP, H\&E, 400X) - Giant cell tumor

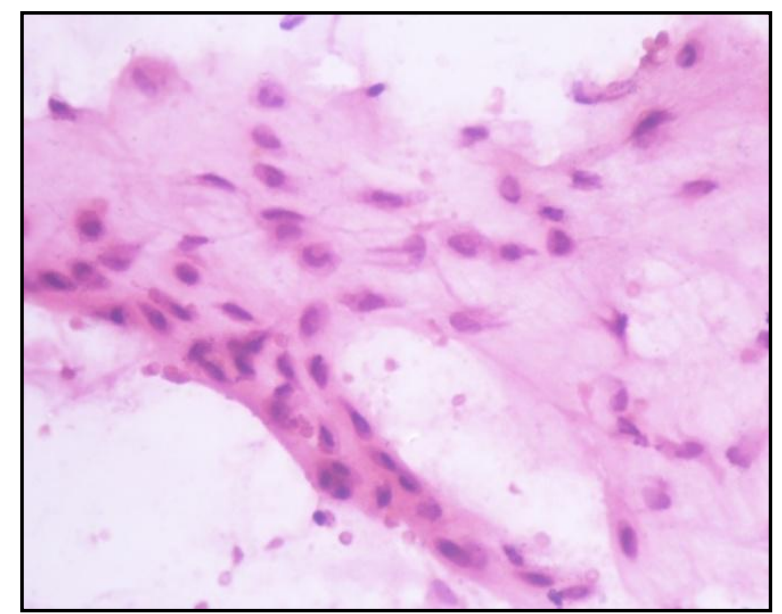

Figure : 4 (A)

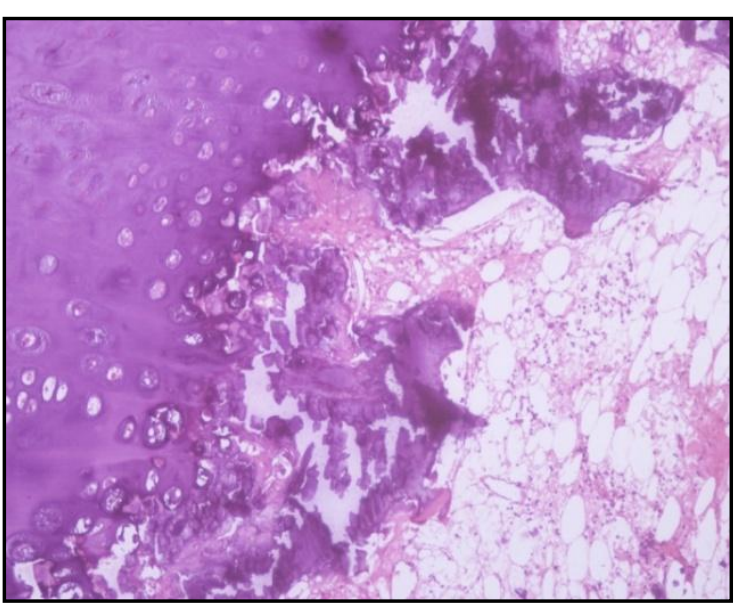

Figure : $4(B)$

Figure: 4 (A) FNA smear : Benign appearing chondrocytes in the background of chondroid ground substance- Benign cartilaginous neoplasm (H\&E, 400X). ( B) Photomicreograph shows mature bone trabeculae covered by cartilaginous cap and normal bone marrow (HP, H\&E, 100X) - - Osteochondroma 


\section{Discussion}

FNAC is a simple and economical technique that can be performed as an outpatient procedure, reducing patient hospitalization and lowering the overall cost of patient care. Complications are few and multiple specimens can be obtained without increased morbidity. Differentiation between a primary and metastatic lesion can also be made by this method. As many malignant primary bone tumours have palpable soft tissue extensions, which are easily aspirated, we used size $23 \mathrm{G}$ needles for most of the aspirations.

In our study, bone tumors were classified in 3 categories (1) Bone forming bone tumors (25 cases, 21.36\%) (2) Cartilage forming bone tumors (22 cases $18.80 \%$ ) (3) other bone tumors (70 cases, $59.82 \%$ ).

Osteoma were found very frequently $(67 \%)$ in $4^{\text {th }}$ decade of life. These results were consistent with the findings of Frassica FJ et al $1996^{5}$. Osteblastoma are found, in $2^{\text {nd }}$ and $3^{\text {rd }}$ decade of life. Among malignant bone tumors, Osteosarcoma was the most commonly occurring tumor $(15.38 \%)$. Osteosarcomas most commonely occur in the knee joint area. In this study, however, it was found that it was more common in 11-20 year old age group. The axial skeleton was not involved in our observation. FNAC was consistent with histopathological diagnosis in 14 (87\%) cases . Out of 18 cases of osteosarcoma, 2 cases were unsatisfactory and 2 cases were misdiagnosed as benign lesion. Out of 16 remaining cases, $87 \%$ cases show cyto-histological correlation. Our results are comparable with previous study of Walaas L et al. $1990^{6}$ and Ayala AG et al. $1995^{7}$

Most of the cases Ewing's sarcoma were found in age 11-20 years (81\%) of age group. Roger LF et al., 2002 studied 106 cases and revealed that Ewing's sarcoma was commonly observed in children and adolescent age group 4-15 years ${ }^{8}$ Ewing's sarcoma is the second commonest primary malignant tumor found in this study. FNAC was consistent with histopathology in Ewing's tumor in $100 \%$ cases
In our study the most common benign tumor was GCT (33\%), .38 cases of Giant cell tumors were studied, $87 \%$ cases were found in 11-30 years of age group. $70 \%$ to $80 \%$ cases occur between the age of 20 and 40 years, ( Enneking et al. 1983 ) ${ }^{9}$. Correctly diagnosed in $91 \%$ of our cases. The most helpful cytologic feature was the attachment of osteoclasts to a cohesive group of mononuclear tumor cells (Merce Jorda M.D et al.2000) ${ }^{4}$.

Total 15 cases of osteochondroma were studied, maximum cases $(60 \%)$ were found in 11-20 years of age group. These tumors were found to occur very frequently in $2^{\text {nd }}$ decade of life. The peak incidence of age was between 6-16 years (Marco et al., 2000) $)^{10}$. 2 cases of osteochondroma were unsatisfactory on cytology, they were diagnosed by histopathology.

No case of chondrosarcoma was found in age below 50 years, $50 \%$ cases were found in $6^{\text {th }}$ decade. Chondrosarcoma is found to occur very frequently in $6^{\text {th }}$ and $7^{\text {th }}$ decade. Campannaci $\mathrm{M}$ et al., 1975 reported that Chondrosarcoma was the most frequently diagnosed bone tumors in the population older than age 50 years ${ }^{11}$. One case of low grade chondrosarcoma was misdiagnosed as chondroma on cytology. Out of 20 cases, 19 cases could be correlated and $95 \%$ correlation was obtained. Chhabra s et al 2010 performed a comparative analysis of fine needle aspiration cytology (FNAC) features of chondroid tumors and their significance in diagnosis and found that FNAC smears interpreted in the light of clinical and radiologic findings demonstrated high diagnostic accuracy ${ }^{13}$.Differential diagnosis between low grade chondrosarcoma and chondroma was not possible on the basis of cytology alone, and therefore in this situation clinical and radiologic correlation was mandatory (Chhabra s et al., 2010) ${ }^{12 .}$

Only one case of Chondroblastoma was seen in $2^{\text {nd }}$ decade of life. These tumors were found to occur very frequently in $2^{\text {nd }}$ decade of life. Patient age ranged from 3 to 72 years of age, $95 \%$ of tumors occur in age between 5 and 25 years. Only one case was found of chondromyxoid fibroma in 
$3^{\text {rd }}$ decade of life. Previous study describe that $>80 \%$ cases occur in $1^{\text {st }}$ and $2^{\text {nd }}$ decade 9 cases of metastatic neoplasm were studied, most of the cases were found above the age of 40 years (Aaron AD et al., 1998) ${ }^{13}$. Previous studies have adequately illustrated the high diagnostic accuracy of FNAC of bone in the diagnosis of metastatic lesions. (James LP et al.1983, Bommer KK et al., $1997)^{14,15}$. In our series, $100 \%$ of metastatic neoplasms were correctly diagnosed by FNAC.

Only 3 cases were found of aneurysmal bone cyst in $2^{\text {nd }}$ decade of life. These tumors were found to occur very frequently in $2^{\text {nd }}$ decade of life. We confronted diagnostic problems, in identifying fibrous lesions such as fibrous dysplasia, mainly due to sampling errors. The fibrous nature of the lesion is considered to be a limiting factor in such cases. Two cases of ossifying fibroma were observed of which were found in $2^{\text {nd }}$ and $3^{\text {rd }}$ decade of life. Only single case of fibrous dysplasia presented and it was found in $3^{\text {rd }}$ decade of life. Fibrous dysplasia most commonly occurs in $3^{\text {rd }}$ decade of life (Frassica et al., 1996) ${ }^{5}$.

A total of 117 cases of bone tumors were studied, after analyzing the data it was revealed that pain and swelling were the most common presenting symptoms of the bone tumors. In this study $81 \%$ of the tumors were associated with pain. B Jorn Widhe et al. (2002), conducted a study on a group of patients and revealed that pain was the initial symptom and swelling was the initial sign of these tumors ${ }^{16}$.

In our study $93 \%$ correlation was obtained, whereas sensitivity, specificity, positive predictive value and negative predictive value were $93.4 \%$, $92.5 \%, 91.4 \%$ and $94.3 \%$ respectively which were comparable with study done by Obiageli E Nnodu et al., revealed accuracy of specific cytological diagnosis was $87.8 \%$.sensitivity and specificity were $95 \%$ and $94 \%$ respectively ${ }^{17}$. Merce Jorda M.D. et al.2000 reported 95\% accuracy. Seventyeight percent of primary bone lesions were correctly diagnosed by cytology 4 .

\section{Conclusion}

FNAC of bone can be used as a simple, cost effective and reliable diagnostic tool for primary diagnosis of bone tumors in consumption with clinical and radiological findings.

\section{References}

1. Springfield DS, Rosenberg A, (Editorial) Biopsy: Complicated and Risky. J Bone and Joint Surg 1996, 78-A:639-643.

2. Kreicbergs A, Bauer HC, Brösjo O, Lindholm J, Skoog L, Soderlund $\mathrm{V}$ :Cytological diagnosis of bone tumours. J Bone Joint Surg 1996,78-B(2):258-263.

3. Martin HE, Ellis EB. Biopsy by needle puncture and aspiration. Ann Surg 1930;92:169- 81 .

4. Merce Jorda M.D. Fine-needle aspiration cytology of bone Cancer Cytopathol, 2000; 90: 47-54.

5. Frassica FJ et al Clinico Pathological features and treatment of Osteoid Osteoma in

children and adolescents. Orthop Clin North Am July 1996; 27(3): 559-74.

6. Walaas et al. Light and electron microscopic examination of fine needle aspirates in the preoperative diagnosis of osteogenic tumors. Diagn Cytopathol 1990; 6: 27-38.

7. Ayala AG et al. Core needle biopsy and fine needle aspiration in the diagnosis of bone and soft tissue lesions. Hematol Oncol Clin North Am 1995; 9: 633-51.

8. Roger LF et al. Ewings sarcoma, A case report of 106 patients, $5^{\text {th }}$ ed. Philadelphia Pa: Lippinco A. 2002; 85-384.

9. Enneking WF: Musculo-skeletal tumor surgery. New York, Churchill Livingstone, 1983; 1345-1380.

10. Marco et al. Cartilagenous tumors. Evaluation and treatment. J am Acad Orthop Surg 2000; (8): 292-304. 
11. Campanacci M et al. Chondrosarcoma : A study of 133 cases, 80 with long term

follow up. Ital J Orthop Traumatol 1975 ; 1: 387-414.

12. Chhabra $\mathrm{S}$ et al. Cytomorphologic features of chondroid neoplasms: a comparative study. Acta Cytol. 2010;54(6):1101-10.

13. Aaron AD. Treatment of metastatic adenocarcinoma of the pelvis and the extremities. J Bone Joint Surg Am. 1998;80:763-4.

14. James LP et al. Fine needle aspiration of bone lesions. Acta Cytol 1983: 27: 559.

15. Bommer KK et al. Fine needle aspiration biopsy in the diagnosis and management of bone lesions. Cancer Cytopathol 1997; 81: 148-56.

16. B Jorn Widhe et al. Initial symptoms and clinical features on Osteosarcoma and Ewing sarcoma. J Bone joint Surge May 2000; 82A : $667-674$.

17. Obiageli E Nnodu et al. Fine needle aspiration cytology of bone tumors. Cyto Journal 2006, 3: 16. 